\title{
POLYGON SHAPED 3G MOBILE BAND ANTENNAS FOR HIGH TECH MILITARY UNIFORMS
}

\author{
R.Muthu Krishnan ${ }^{1}$, G.Kannan ${ }^{2}$ \\ ${ }^{1}$ Research Scholar, Department of ECE, B.S.Abdur Rahman University, Chennai \\ ${ }^{2}$ Assistant Professor, Department of ECE, B.S.Abdur Rahman University, Chennai. \\ Email: pearlkrish002@gmail.com ${ }^{1}$, kannan_ins@yahoo.co.in²
}

\begin{abstract}
Smart Textiles integrated with communicating components have been used in the military for many applications. The wearable antenna can be attached or embedded into smart textiles which could be used for communication between combat soldiers in the battlefield. This paper presents the design of three different polygon shaped patch antennas operating on $3 \mathrm{G}$ Mobile Band frequency $2100 \mathrm{MHz}$ embedded on three different dielectric constant materials for Military applications. The proposed polygon shaped patch antenna introduces horizontal slit in its patch to improve the antenna performance. The slit length is varied and their corresponding effect on the antenna performance is analyzed.
\end{abstract}

Keywords: Wearable antenna, Polygon shape patch antenna, smart textiles

\section{Introduction}

The smart textiles can sense, react, and adapt themselves to the environmental surroundings. Smart Textiles help combat soldiers to take critical decisions in the battlefield with lighter electronic wearable devices [1]. The wearable antenna is one of the essential components of the smart textiles or high tech military uniforms. For communication between combat soldiers in the battlefield, the proposed three wearable antennas operating in $3 \mathrm{G}$ network frequency $2100 \mathrm{MHz}$ could be used. In the proposed work, the main objective is to a design wearable antenna which could be embedded in the jeans substrate. The proposed wearable antenna would be operated in the $2100 \mathrm{MHz}$ frequency for military applications. The dielectric constant of the jeans substrate varies in the range 1.6 to 1.7 . This work proposes three different structure antennas for dielectric constant values 1.6, 1.65 and 1.7 with a substrate thickness of $0.57 \mathrm{~mm}$.

Development of four rectangular patch antennas employing different varieties of cotton and polyester clothing for on-body wireless communications in the 2.45 $\mathrm{GHz}$ WLAN band were designed in [2]. Slit-cut stacked equilateral triangular microstrip antenna (ETMA) were presented in [3]. The performance of a $2 * 2$ microstrip patch array under crumpling conditions was presented in [4]. Using resonance method, the dielectric constant of the fabric material can easily be extracted from the measured resonant frequency of the patch radiator. This technique was reported in [5].Performance degradation due to bending and crumpling condition of the wearable antenna was reported in [6].The performance of a dual-band coplanar patch antenna integrated with an electromagnetic band gap substrate was described in [7].Design of a wearable dualband patch antenna for operating in the GSM-900 and 1800 bands was presented in [8].

For experimental measurement, among three antennas one antenna is chosen and fabricated and their various parameters are tested using vector network analyzer. The organization of the paper is as follows the antenna design parameters are explained in section 2. The simulation results and measured results are presented in section 3 and section 4 respectively and the conclusion is given in section 5 .

\section{Antenna Design}

In the proposed work, three polygon shaped textile patch antennas are designed. Initially proposed antenna patch length $\left(\lambda_{\mathrm{g}} / 2\right)$ is computed using the standard length and width expression of a square patch, given in [9] where $\lambda_{\mathrm{g}}$ is the guided wavelength at $2100 \mathrm{MHz}$.

$$
\lambda_{g}=\frac{\mathrm{c}}{\mathrm{f} \sqrt{\varepsilon_{\mathrm{r}}}}
$$

Where

$$
\begin{aligned}
& \mathrm{c}-\text { Velocity of light, } \\
& \varepsilon_{\mathrm{r}}-\text { Dielectric constant of the substrate, } \\
& \mathrm{f}-\text { Operating Frequency. }
\end{aligned}
$$

For proposed antennas, Guided wavelength $\left(\lambda_{\mathrm{g}}\right)$ is calculated by applying $\varepsilon_{\mathrm{r}}=1.6,1.65$ and 1.7 values in above equation and then the length of the patch $\left(\lambda_{\mathrm{g}} / 2\right)$ is calculated by taking half of the guided wavelength. The length of the patch is approximated to $60 \mathrm{~mm}$. This square shape is then transformed into polygon shape by cutting out portions in the corners, based on the Pythagoras theorem to reduce the patch area.

By introducing a proper slit length and slit position, good impedance match can be achieved [9]. The slit is introduced in the top edge of the patch. Various 
techniques involved to determine the optimized feed location to the microstrip patch antenna. In this proposed paper, Equation (2) is given to compute the optimized feed location for the polygon shaped antenna in next section.

\section{Results and Discussion}

In this paper, three different patch antennas were designed for three different dielectric constant materials 1.6, 1.65 , and 1.7 which represented as Antenna 1, 2, 3 respectively in the following section.

\section{ANTENNA 1}

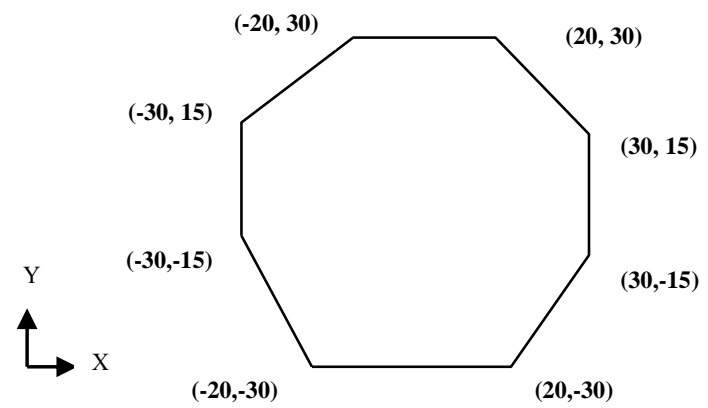

Fig. 1.1 Polygon shaped patch Antenna 1-Topology

Topology of the Polygon shaped patch Antenna 1 which operates at $2100 \mathrm{MHz}$ for 1.6 Dielectric Constant with $0.57 \mathrm{~mm}$ thickness is shown in Fig. 1.1. The dimension of the Antenna 1 patch is shown in $(\mathrm{x}, \mathrm{y})$ coordinates as the patch is centered in the origin point $(0,0)$ in Fig.1.1. All the dimensions have represented in millimeter $(\mathrm{mm})$ in Fig.1.1. In the proposed system, optimized feed location $\left(\mathrm{X}_{0}, \mathrm{Y}_{0}\right)$ calculated using the below equation.

$$
\left(\mathrm{X}_{0}, \mathrm{Y}_{0}\right)=\left(\frac{\mathrm{L}}{2}-\frac{\mathrm{L}}{8}, \frac{\mathrm{L}}{2}\right)
$$

Here $\mathrm{L}$ represents the length of the patch which is $60 \mathrm{~mm}$. $\left(\mathrm{X}_{0}, \mathrm{Y}_{0}\right)$ determines the coordinates for optimized feed position in the patch. For the proposed work optimized feed position is $(-22.5,0)$ and loss tangent value is 0.025 . Antenna 1 is simulated using HFSS software which is shown in Fig. 1.2 and its $\mathrm{S}_{11}$ Response is shown in Fig.1.3.

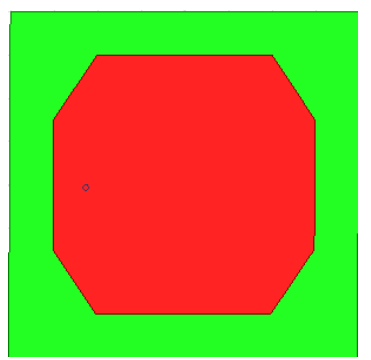

Fig. 1.2 Structure of Antenna 1 using HFSS

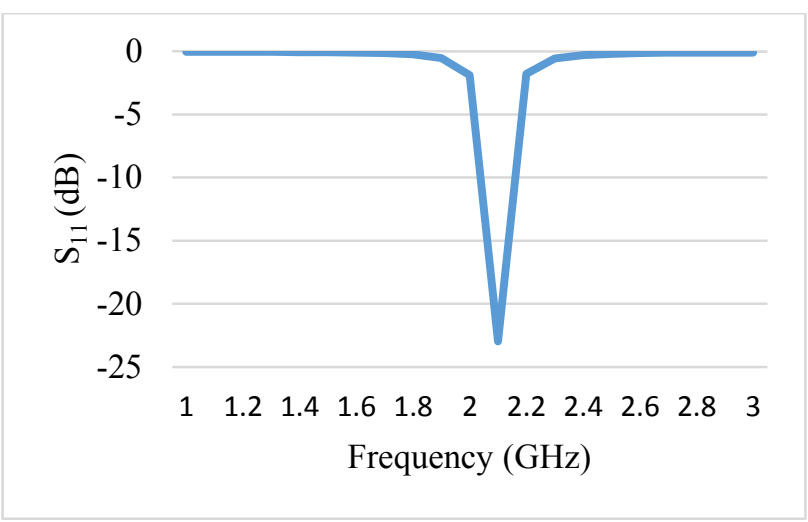

Fig.1.3 $\mathrm{S}_{11}$ Response of the Antenna 1

Table 1.1 Analysis of different parameters for Antenna 1

\begin{tabular}{|c|c|c|c|c|c|}
\hline $\begin{array}{l}\text { Dielectric } \\
\text { Constant }\left(\varepsilon_{\mathrm{r})}\right.\end{array}$ & $\begin{array}{c}\mathrm{S}_{11} \\
(\mathrm{~dB})\end{array}$ & $\begin{array}{c}\text { Band } \\
\text { width } \\
(\mathrm{MHz})\end{array}$ & VSWR & $\begin{array}{c}\text { Gain } \\
(\mathrm{dB})\end{array}$ & $\begin{array}{c}\text { Freq } \\
(\mathrm{MHz})\end{array}$ \\
\hline 1.60 & -20 & 80 & 1.19 & $\begin{array}{c}1.606 \\
3\end{array}$ & 2100 \\
\hline 1.61 & -30 & 90 & 1.07 & 1.414 & 2100 \\
\hline 1.62 & -24 & 85 & 1.13 & 1.11 & 2100 \\
\hline 1.63 & -16 & 78 & 1.43 & $\begin{array}{c}1.003 \\
2\end{array}$ & 2100 \\
\hline
\end{tabular}

The Antenna 1 structure is simulated and its various parameters such as bandwidth, VSWR, and gain are analyzed over dielectric constant range 1.6 to 1.7 and its best performance is tabulated in Table $1.1 \mathrm{~S}_{11}$ Response (return loss) for Antenna 1 structure embedded on dielectric substrate with $1.6,1.61,1.62$ and 1.63 dielectric constant value is $-20 \mathrm{~dB},-30 \mathrm{~dB},-24 \mathrm{~dB}$ and $-16 \mathrm{~dB}$ respectively. It shows the $S_{11}$ response for the four dielectric constant value had better results because $S_{11}$ should be lesser than $-10 \mathrm{~dB}$. VSWR must be lower than 2 for the good operating antenna. Simulation result shows that Antenna 1 has VSWR value of $1.19,1.07,1.13$ and 1.24 for $1.6,1.61,1.62$ and 1.63 respectively. As the simulation result shows, using Antenna 1 structure on a dielectric substrate having 1.6 dielectric constant value have a resonance at $3 \mathrm{G}$ Mobile Band 2100 $\mathrm{MHz}$ with Bandwidth of $80 \mathrm{MHz}$ again it widens to $90 \mathrm{MHz}$ Bandwidth when we use the same structure for 1.61 dielectric constant substrate in the simulation. But, Bandwidth gradually reduces in 1.62 and 1.63 to $85 \mathrm{MHz}$ and $70 \mathrm{MHz}$ respectively. Fig 1.4 shows 2D radiation pattern of the Antenna 1 at $2100 \mathrm{MHz}$. Antenna 1 shows good gain $1.6061 \mathrm{~dB}$ at $2100 \mathrm{MHz}$ which is enough for short range communication. It is for realized gain (far-field) in $2100 \mathrm{MHz}$. As a conclusion, we can use Antenna 1 structure for 1.6 dielectric constant substrate because it shows better results in 1.6 value in the range of 1.6 to 1.7 dielectric constant value. Antenna 1 also shows good performance in 1.61 dielectric constant value but its gain $(1.4 \mathrm{~dB})$ is low 
compared to a gain in 1.6 dielectric constant value. The antenna 1 structure works well on the dielectric constant ranges $1.60,1.61,1.62$, and 1.63 on analyzing over the dielectric constant range 1.6 to 1.7 .

Circular polarization can be obtained by cutting diagonal corners in the square patch but in proposed three antennas, due to cutting out all four corners to get polygon shape it possess regular linear polarization.

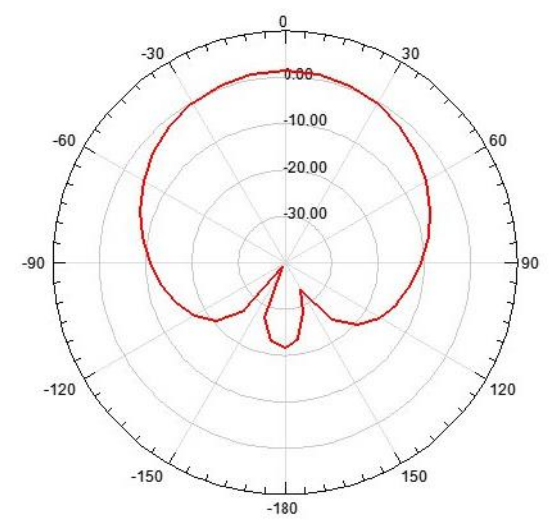

Fig.1.4 2D Radiation Pattern of the Antenna 1

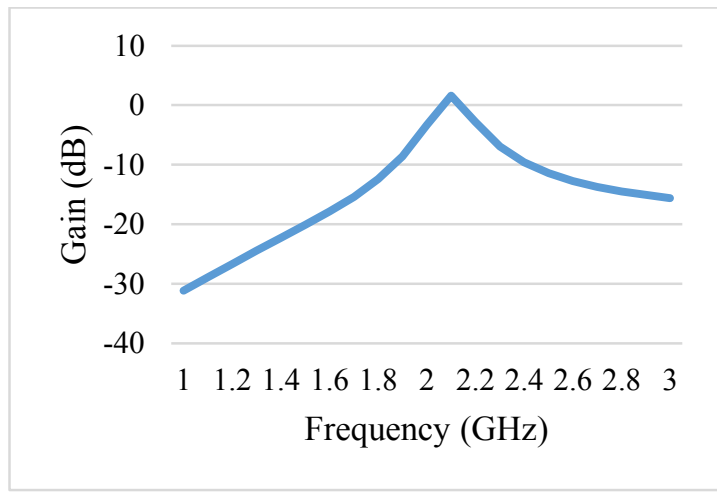

Fig.1.5 Gain vs Frequency relationship of Antenna 1

Fig 1.5 shows that Gain vs Frequency graph from that it is clearly understood when comparing to other frequency, Antennal have good gain in $2.1 \mathrm{GHz}$. It also shows that good impedance matching occurs in $2100 \mathrm{MHz}$ frequency.

\section{ANTENNA 2}

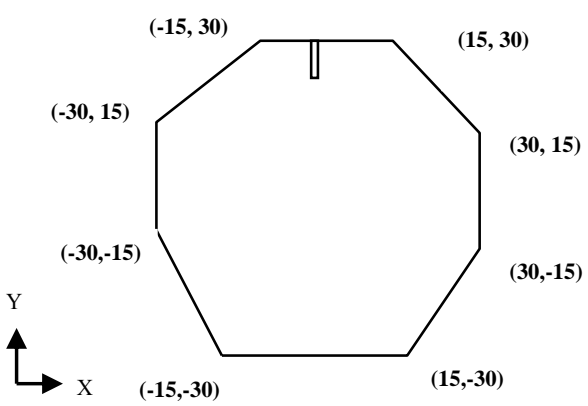

Fig.1.6 Polygon shaped patch Antenna 2-Topology
Topology of the Polygon shaped patch Antenna 2 which is designed to operate on $2100 \mathrm{MHz}$ for 1.65 Dielectric Constant with $0.57 \mathrm{~mm}$ thickness is shown in Fig. 1.6. The dimension of Antenna 2 patch is shown in $(x, y)$ coordinates as the patch is centered in the origin point $(0,0)$ in Fig.1.6.All the dimensions have represented in millimeter $(\mathrm{mm})$ in Fig. 1.6

Feed location point for this antenna is $(-22.5,0)$ which is calculated using equation (2) and loss tangent value is 0.025 . The slit is introduced in the top edge of this antenna to improve antenna performance. Slit length is varied by keeping constant width $1 \mathrm{~mm}$ and their effect on the antenna performance is shown in Fig.1.8. If slit length (a) $4 \mathrm{~mm}$ is introduced in antenna structure it gives $S_{11}$ response of $-20 \mathrm{~dB}$ and it reduces to $-17 \mathrm{~dB}$ and $-12 \mathrm{~dB}$ when we increase slit length to $4.5 \mathrm{~mm}$ and $5 \mathrm{~mm}$ respectively. By introducing slit length with $4 \mathrm{~mm}$ length and width $1 \mathrm{~mm}$ helps antenna 2 structure to achieve good impedance matching so it increases the antenna performance. By increasing slit length it results in poor antenna performance. Antenna 2 is simulated using HFSS software which is shown in Fig. 1.7 and its $S_{11}$ Response is shown in Fig.1.8.

Table 1.2 Analysis of different parameters for Antenna 2

\begin{tabular}{|c|c|c|c|c|c|}
\hline $\begin{array}{l}\text { Dielectric } \\
\text { Constant }\left(\varepsilon_{\mathrm{r})}\right.\end{array}$ & $\begin{array}{c}\mathrm{S}_{11} \\
(\mathrm{~dB})\end{array}$ & $\begin{array}{c}\text { Band } \\
\text { width } \\
(\mathrm{MHz})\end{array}$ & VSWR & $\begin{array}{c}\text { Gain } \\
(\mathrm{dB})\end{array}$ & $\begin{array}{c}\text { Freq } \\
(\mathrm{MHz})\end{array}$ \\
\hline 1.64 & -19 & 65 & 1.24 & 1.14 & 2100 \\
\hline 1.65 & -20 & 75 & 1.20 & 1.44 & 2100 \\
\hline
\end{tabular}

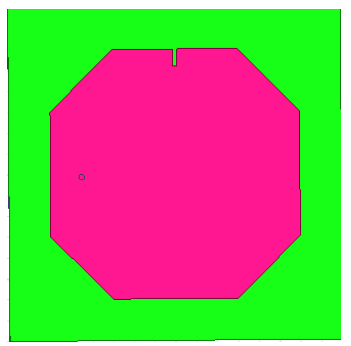

Fig. 1.7 Structure of Antenna 2 using HFSS

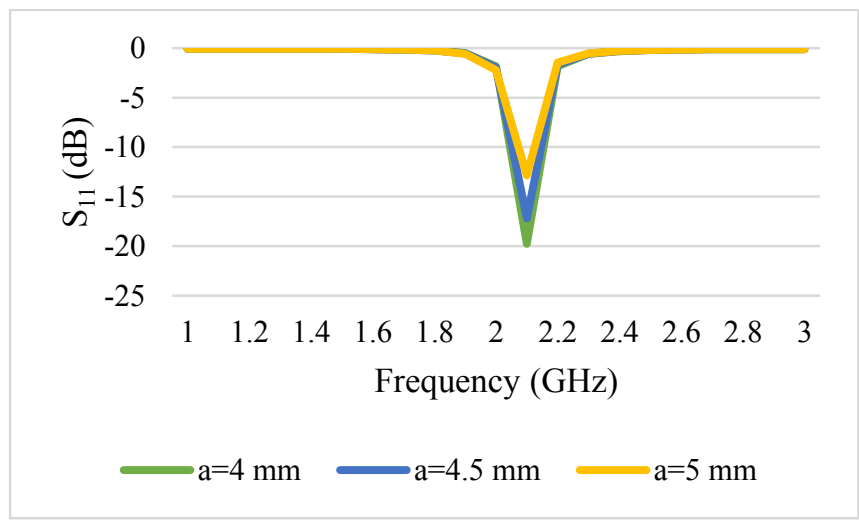

Fig.1.8. S $_{11}$ Response of the Antenna 2 
The Antenna 2 structure is simulated and its various parameters such as bandwidth, VSWR, and gain are analyzed over the dielectric constant range 1.6 to 1.7 and its best performance is tabulated in Table 1.2. $\mathrm{S}_{11}$ Response of Antenna 2 structure embedded on a dielectric substrate with 1.64 and 1.65 dielectric constant value is- $19 \mathrm{~dB}$ and $-20 \mathrm{~dB}$ respectively. It shows the $S_{11}$ response for the two dielectric constant value is good because $S_{11}$ should be lesser than -10 dB. VSWR must be lower than 2 for the good operating antenna.

Simulation result shows that Antenna 2 have VSWR value of 1.24 and 1.20 for 1.64 and 1.65 respectively. As the simulation result shows, Antenna 2 have a resonance at $3 \mathrm{G}$ Mobile Band $2100 \mathrm{MHz}$ with a bandwidth of $65 \mathrm{MHz}$ in 1.64 dielectric constant value again it widens to $75 \mathrm{MHz}$ bandwidth when we use the same structure for 1.65 dielectric constant substrate in the simulation. Fig 1.9 shows 2D radiation pattern of the Antenna 2 at $2100 \mathrm{MHz}$. Antenna 2 shows well realized gain (far-field) $1.44 \mathrm{~dB}$ at $2100 \mathrm{MHz}$ which is enough for short range communication. As a conclusion, we can use Antenna 2 structure for 1.65 dielectric constant substrate because it shows better results in 1.65 value in the range of 1.6 to 1.7 value .This antenna also works well on dielectric constant 1.64 but bandwidth is lesser compared to 1.65 dielectric constant substrate.

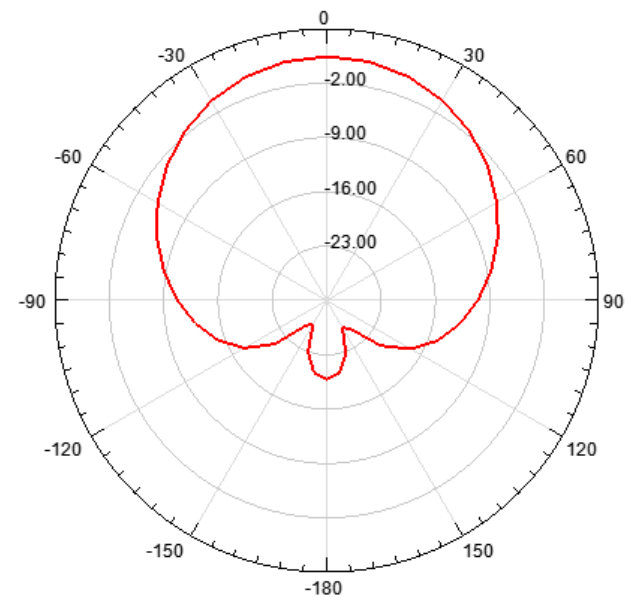

Fig.1.9 2D Radiation Pattern of the Antenna 2

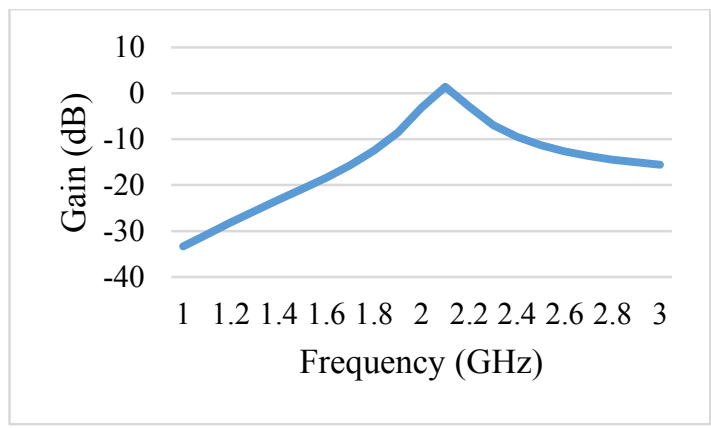

Fig 1.10 Gain vs Frequency Relationship of Antenna 2
Fig 1.10 presents that Gain vs Frequency graph from that it is clearly understood when comparing to other frequency, Antenna 2 have good gain in $2.1 \mathrm{GHz}$. It also shows that good impedance matching occurs in $2100 \mathrm{MHz}$ frequency.

\section{ANTENNA 3}

Topology of the Polygon shaped patch Antenna 3 which operates at $2100 \mathrm{MHz}$ for 1.7 Dielectric Constant with 0.57 $\mathrm{mm}$ dielectric material thickness is shown in Fig. 1.11. The dimension of the Antenna 3 patch is shown in $(x, y)$ coordinates as the patch is centered in the origin point $(0,0)$ in Fig.1.11. All the dimensions have represented in millimeter (mm) in Fig.1.11

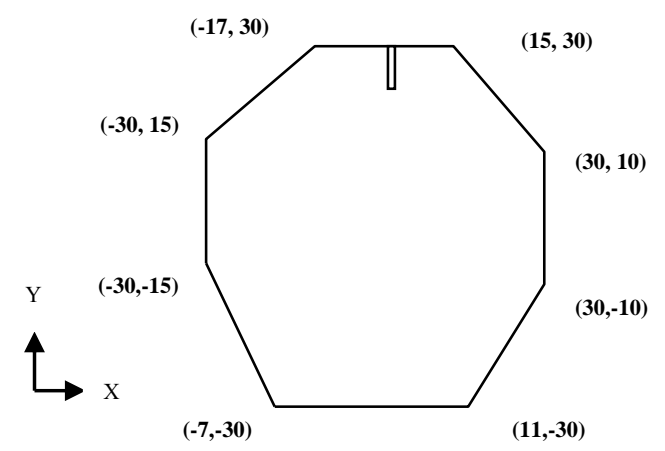

Fig. 1.11 Polygon shaped patch Antenna 3-Topology

Feed location for this Antenna is $(-22.5,0)$ which is computed using equation (2) and loss tangent value is 0.025 . The slit is introduced in the top edge of this antenna to improve antenna performance. Slit length is varied by keeping constant width $2 \mathrm{~mm}$ and their effect on the antenna performance is shown in Fig.1.13. If slit length (b) $4.5 \mathrm{~mm}$ is introduced in antenna structure it gives an $S_{11}$ response of $-13 \mathrm{~dB}$ and it increases to $-17 \mathrm{~dB}$ and $-21 \mathrm{~dB}$ when we increase slit length to $5 \mathrm{~mm}$ and $5.5 \mathrm{~mm}$ respectively. By introducing slit length with $5.5 \mathrm{~mm}$ length and width $2 \mathrm{~mm}$ in Antenna 3 results in good performance. Antenna 3 is simulated using HFSS software which is shown in Fig. 1.12 and its $\mathrm{S}_{11}$ Response is shown in Fig.1.13.

Table 1.3 Analysis of different parameters for Antenna 3

\begin{tabular}{|c|c|c|c|c|c|}
\hline $\begin{array}{l}\text { Dielectric } \\
\text { Constant }\left(\varepsilon_{\mathrm{r})}\right.\end{array}$ & $\begin{array}{c}\mathrm{S}_{11} \\
(\mathrm{~dB})\end{array}$ & $\begin{array}{c}\text { Band } \\
\text { width } \\
(\mathrm{MHz})\end{array}$ & VSWR & $\begin{array}{c}\text { Gain } \\
(\mathrm{dB})\end{array}$ & $\begin{array}{c}\text { Freq } \\
(\mathrm{MHz})\end{array}$ \\
\hline 1.7 & -21 & 80 & 1.14 & 1.17433 & 2100 \\
\hline
\end{tabular}

The Antenna 3 is simulated and its various parameters such as bandwidth, VSWR, and gain are analyzed over dielectric constant range 1.6 to 1.7 and its best performance is tabulated in Table 1.3. 


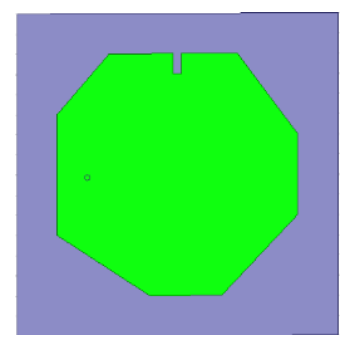

Fig. 1.12 Structure of Antenna 3 using HFSS

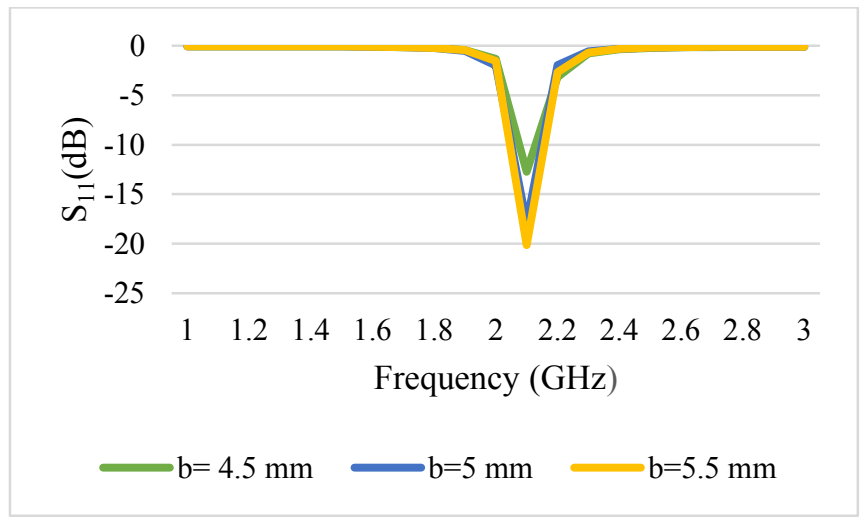

Fig $1.13 S_{11}$ Response of the Antenna 3

As the simulation result shows, Antenna 3 radiates well at $2100 \mathrm{MHz}$ only for 1.7 dielectric constant substrate which results in $80 \mathrm{MHz}$ bandwidth and VSWR 1.14 (must be < 2).Fig 1.14 shows $2 \mathrm{D}$ radiation pattern of the Antenna 3 at $2100 \mathrm{MHz}$. Antenna 3 shows well realized gain (far-field) $1.17 \mathrm{~dB}$ at $2100 \mathrm{MHz}$ which is enough for short range communication.

Fig 1.15 shows that Gain vs Frequency graph from that it is clearly understood when comparing to other frequency, Antenna 3 have good gain in $2.1 \mathrm{GHz}$. It also shows that good impedance matching occurs in $2100 \mathrm{MHz}$ frequency.

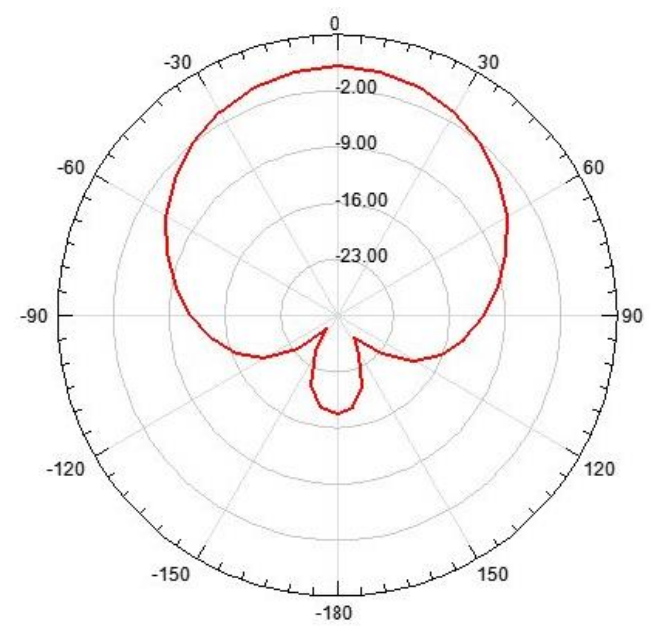

Fig. 1.14 2D Radiation Pattern of the Antenna 3

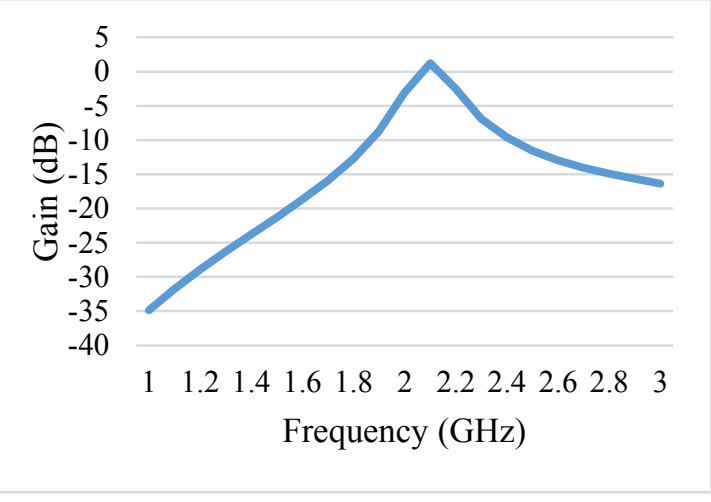

Fig.1.15 Gain vs Frequency relationship of the Antenna 3

Table 1.4 Comparison between three antennas

\begin{tabular}{|l|l|c|c|}
\hline Antenna & \multicolumn{1}{|c|}{$\begin{array}{c}\text { Coverage of } \\
\text { Dielectric } \\
\text { constant values }\end{array}$} & $\begin{array}{c}\text { Bandwidth } \\
(\mathrm{MHz})\end{array}$ & $\begin{array}{c}\text { Gain } \\
(\mathrm{dB})\end{array}$ \\
\hline Antenna 1 & $\begin{array}{l}1.6,1.61,1.62, \\
1.63\end{array}$ & 90 & 1.61 \\
\hline Antenna 2 & $1.64,1.65$ & 75 & 1.44 \\
\hline Antenna 3 & 1.7 & 80 & 1.14 \\
\hline
\end{tabular}

Comparing the three proposed antennas, Antenna 1 structure covers four dielectric constant values 1.6, 1.61, 1.62 and 1.63 over the dielectric constant range 1.6 to 1.7 with good performance. Antenna 2 structure works well in 1.64 and 1.65 dielectric constant substrate. Antenna 3 shows good performance in 1.7 dielectric constant substrate. Antenna 1 has good performance in terms of bandwidth and gain when compared to other two antennas. It can be observed that three proposed antennas were capable of covering most of the dielectric constant value possessed by jeans material. By choosing any jeans material with 0.57 $\mathrm{mm}$ thickness and having this three structure we can fabricate antenna which could be embedded into smart textiles for communication.

\section{Experimental Results}

From the simulated three different proposed antennas, Antenna 1 which is designed for 1.6 dielectric constant material is fabricated and tested. The antenna is tested using vector network analyzer. The Fabricated antenna is shown in Fig.1.16. The patch of the antenna is fabricated using $0.1 \mathrm{~mm}$ copper sheet. Jeans material having dielectric constant 1.6 with $0.57 \mathrm{~mm}$ thickness is chosen as a dielectric substrate for the fabricated antenna. The measured VSWR value for the fabricated antenna is 1.6. The measured $\mathrm{S}_{11}$ response for the fabricated antenna $-16 \mathrm{~dB}$ which is shown in Fig 1.18. 


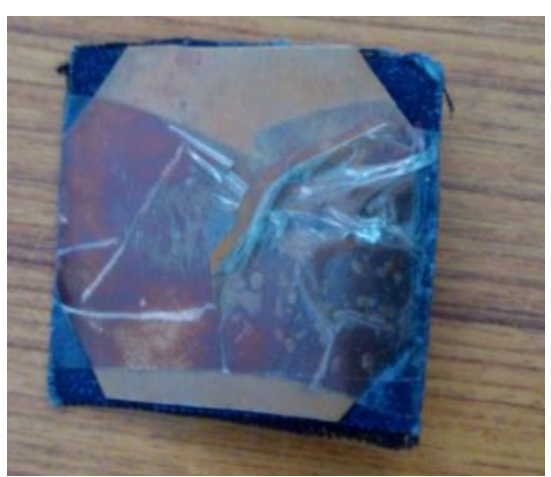

Fig.1.16 Front view of fabricated antenna

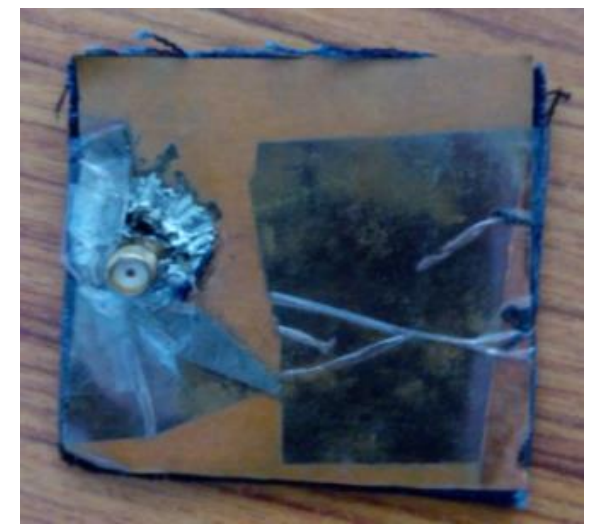

Fig.1.17 Rear view of fabricated antenna

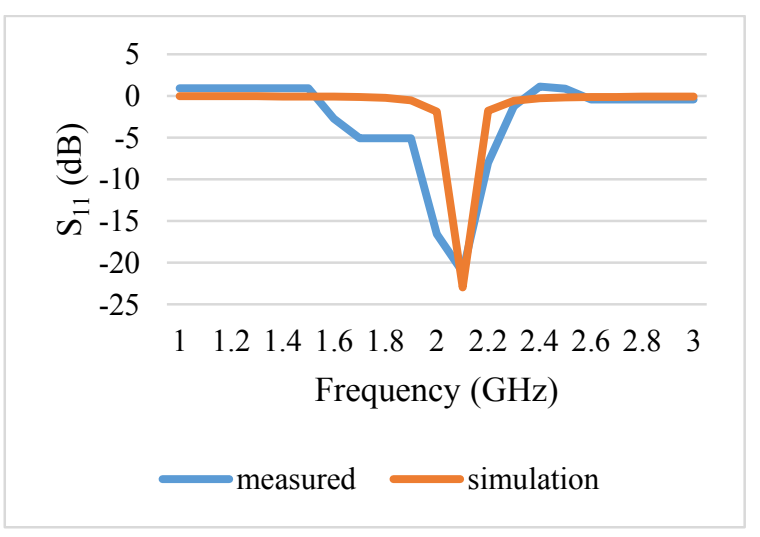

Fig.1.18. S11 Response of measured and simulated results of Antenna 1

Comparing simulation and experimental results of Antenna 1 shows that there is good matching between them. Fabricated antenna works well in desired frequency 2100 $\mathrm{MHz}$ with $-16 \mathrm{~dB}$ return loss. Comparison between the $\mathrm{S}_{11}$ response of measured and simulated results of Antenna 1 is shown in Fig.1.18.

\section{Conclusions}

Three polygon shaped patch antennas for $3 \mathrm{G}$ mobile band $2100 \mathrm{MHz}$ were designed and their performance over the dielectric constant range 1.6 to 1.7 was analyzed. Simulation and measured results clearly showed that significant characteristics of the antenna such that reflection coefficient, gain, bandwidth were much better which make it suitable for embedding antenna into smart textiles. Therefore, proposed antennas could be further used in high tech military uniforms for communication in the battlefield.

\section{Acknowledgement}

The researchers record their sincere thanks to the Department of Electronics and Communication Engineering, B.S. Abdur Rahman University, Chennai, India for their constant support and providing necessary facilities to carry out this investigation successfully.

\section{References}

[1] O. Sahin, 0. Kayacan, E. Yazgan Bulgun, 'Smart Textiles for Soldier of the Future' Defence Science Journal, vol. 55, no. 2, April 2005, pp. 195-205.

[2] S. Sankaralingam and B. Gupta,'Development of Textile Antennas for Body Wearable Applications and Investigations on Their Performance under Bent Conditions' Progress In Electromagnetics Research B, vol. 22, 53-71, 2010.

[3] Prabal Pratap, R.S. Bhatia, Binod Kumar, Mohd. Nazir, and Saurabh Pratap ,'Design and analysis of slit-cut stacked equilateral Triangular Microstrip Patch antenna' Defence Science Journal, vol. 65, no. 3, pp. 240-244, may 2015.

[4] Qiang Bai, Jonathan Rigelsford, and Richard Langley, 'Crumpling of Microstrip Antenna Array' IEEE Transactions on Antennas and Propagation, vol. 61, no. 9, sep 2013.

[5] Sankaralingam .S and Gupta .B, 'Determination of dielectric constant of fabric materials and their use as substrates for design and development of antennas for wearable applications' IEEE Trans. Instrum. Meas., vol. 59, no. 12 , pp. 3122-3130, 2010.

[6] Salonen.P and Rahmat-Samii .Y, 'Textile antennas: Effects of antenna bending on input matching and impedance bandwidth' IEEE Aerosp. Electron. Syst. Mag., vol. 22, no. 12, pp. 18-22, 2011.

[7] Watanabe .T and Iwasaki .H, 'Wearable finger dual-band antenna for BAN' in Proc. IEEE-APS Top. Conf., pp. 5154, 2012.

[8] Esther Florence Sundarsingh, Sangeetha Velan, Malathi Kanagasabai, Aswathy K. Sarma, Chinnambeti Raviteja, and M. Gulam Nabi Alsath, 'Polygon-Shaped Slotted Dual-Band Antenna for Wearable Applications' IEEE Antennas and Wireless Propagation Letters, vol. 13, 2014. 
[9] Balanis. A.C, Antenna Theory: Analysis and Design, $3^{\text {rd }}$ ed. Hoboken, NJ, USA: Wiley, 2012.

[10] Alomainy .A, Hao .Y, Owadally .A, Parini .C.G, Nechayev.Y, Constantinou .C.C, and Hall .P.S, 'Statistical analysis and performance evaluation for on-body radio propagation with microstrip patch antennas' IEEE Trans. Antennas Propag., vol. 55, no. 1, pp. 245-248, 2007.

[11] Alomainy.A, Sani .A, Rahman .A, Santas .J.G , and Hao .Y, 'Transient characteristics of wearable antennas and radio propagation channels for ultrawideband body-centric wireless communications' IEEE Trans. Antennas Propag., vol. 57, no. 4, pp. 875-884, 2009.

[12] Chen. M and Chen .C, 'A compact dual-band GPS antenna design' IEEE Antennas Wireless Propag. Lett, vol. 12, pp. 245-248, 2012.

[13] Osman,M. K. A, Rahim,M. Azfar, Samsuri .N.A, Zubir .F, and Kamardin .K, 'Design, implementation, and performance of ultra-wideband textile antenna' Prog. Electromagn. Res. B, vol. 27, pp. 307-327, 2011.

[14] Qian .K and Tang .X (2011), 'Compact LTCC dualband circularly polarized perturbed hexagonal microstrip antenna' IEEEAntennas Wireless Propag. Lett, vol. 10, pp. 1212-1215, 2011.

[15] Wasife.K.E, 'Power density and SAR in multi-layered life tissue at Global System Mobile (GSM) frequencies' J. Electromagn. Anal. Appl., vol. 3, no. 8, pp. 328-332, 2011

[16] Zhu.S and Langley.R, 'Dual-band wearable textile antenna on an EBG substrate' IEEE Trans. Antennas Propag., vol. 57, no. 4, pp. 926-935, 2009.

[17] Zhu.S and Langley.R, 'Tri-band wearable textile antenna on an EBG substrate' IEEE Trans. Antennas Propag., vol. 117, no. 4, pp. 753-759, 2011. 